\title{
Comparative analysis of hematological parameters in well-trained athletes and untrained men
}

\author{
Koç H. ${ }^{1 \mathrm{ABCDE}}$, Özen G. ${ }^{2 \mathrm{ACDE}}$, Abanoz H. ${ }^{1 \mathrm{ABE}}$, Pulur A. ${ }^{3 \mathrm{ABE}}$ \\ ${ }^{1}$ Department of Coaching Education, Faculty of Sport Sciences, Çanakkale Onsekiz Mart University, Çanakkale, \\ Turkey \\ ${ }^{2}$ Department of Physical Education and Sports Teaching, Faculty of Sports Sciences, Çanakkale Onsekiz Mart \\ University, Çanakkale, Turkey \\ ${ }^{3}$ Department of Physical Education and Sports Teaching, Faculty of Sport Sciences, Gazi University, Ankara, \\ Turkey
}

Authors' Contribution: A - Study design; B - Data collection; C - Statistical analysis; D - Manuscript Preparation; E - Funds Collection

\begin{abstract}
Purpose: $\quad$ The purpose of current study was to investigate the hematology parameters of male athletes who had exercised regularly for five years and sedentary male university students.

Material: $\quad$ The sample consisted of 18 well-trained and 18 sedentary male university students aged between 20 and 22 years old. The peripheral fasting blood samples were collected from each participant. Laboratory analysis was made to determine the red and white blood cells counts and their concentration percentage.

Results: $\quad$ The means of white blood cell, lymphocyte, monocyte counts, and lymphocyte and monocyte percentages were significantly lower in the well-trained group while the means of hemoglobin count, mean cell hemoglobin, red blood cell distribution width were significantly lower in sedentary group $(p>.05)$. However, no statistically significant difference between groups was found in red blood cell counts, granulocyte counts, and granulocyte percentages $(p>.05)$.

Conclusions: Our findings show that athletes participating in the long-term regular exercise have the high level of the concentration of red blood cells subtypes and the low level of the concentration of white blood cells subtypes when compared to their sedentary peers. Because their hematologic values remain within the reference range for healthy people, these differences do not pose any serious clinical problems for athletes. The high RBC and low WBC subtypes values of athletes may be explained by chronic adaptation to long-term exercise.

Keywords: blood, exercise, hematology, sports, athletes.
\end{abstract}

\section{Introduction}

Nowadays, it is the known fact that physical activity through regular exercise had positive effects on physical, physiological, psychological, and other health outcomes. Scientific evidence exists that these are positive effects caused by the acute and chronic effects of regular exercise on different body systems. Regular exercise leads to increase of physical capacity by improving the efficiency of the cardiovascular, muscular, respiratory and neural systems. Blood is widely used as an indicator to evaluate the effect of exercise on the function of body systems such as the cardiovascular, immune, and endocrine system. Blood is composed of three main cell types including red blood cells (RBCs) or erythrocytes $(99 \%)$, platelets $(<$ $1 \%)$ and white blood cells (WBCs) or leukocytes $(<1 \%)$ $[1,2]$. These cells play an important role in maintaining a homeostatic balance. RBCs have a primary role in the transport of respiratory gases. Hemoglobin (HGB) that contained in the red blood cells carries oxygen from the lungs to the tissues and thereby provides needed oxygen in efficient energy production for muscle contractions and sustained contractions during the prolonged physical activity and exercise. Also, RBCs enable the transport of carbon dioxide out of tissues, normalization of blood $\mathrm{pH}$ and they carrier metabolites such as lactate released from skeletal muscles during high-intensity exercise $[2$, 3]. It has been considered that a reduction in the count of

\footnotetext{
(c) Koç H., Özen G., Abanoz H., Pulur A., 2018
}

doi:10.15561/18189172.2018.0506
RBCs, HGB concentration, or oxygen-binding capacity of HGB may negatively impact on physical performance. WBC is important components of the immune system [4]. Their primary role is to protect against pathogenic bacteria, viruses, other foreign materials entering the body, infections and damaged cells that threaten the normal function of tissues in the body [5].

Regular exercise and physical activity are considered as an important regulator of blood cells and their functions $[6,7]$. On the other hand, physical inactivity and sedentary lifestyles is often accompanied by hematologic disorders such as hypovolemia, hematocrit (HCT) and $\mathrm{Ph}$ imbalance [8-10]. It was reported that there are different findings that emerge with regard to hematologic parameters in the peripheral blood during and after exercise and physical activity [11]. However, intensity, type, frequency, and duration of exercise, genetic factors, the physiologic characteristics and lifestyle of subjects are closely related to acute and chronic differences in hematologic parameters $[12,13]$. In scientific researches, these factors might account for the inconsistent results in blood parameters of athletes. In order to make an accurate inference about the effect of physical activity through regular exercise on blood parameters, it should be investigated the long-term effect of regular exercise and physical activity on these parameters for different ages and population groups. In the literature, the many of studies have usually focused the acute and short-term effect of exercise and physical activity on hematologic 
parameters [11,14-17]. The studies conducted in this field dictated an increase in WBC count and a decrease in $\mathrm{RBC}$ count as a result of regular exercise [14,15]. On the other hand, some researchers reported opposite or contradictory findings [18-20]. In summary, there are controversial about how exercise affects the hematology. Therefore, it should be investigated in more detail and in different population over different time periods. To this end, the present study compared hematology parameters of male athletes who doing regular exercise for five years and sedentary university students in the same age group and gender. We hypothesized that regular exercise caused the permanent changes in the hematologic parameters of athletes in long-term.

\section{Materials and Methods}

Subjects

Eighteen well-trained male athletes from basketball, handball, and volleyball and 18 healthy and sedentary male university students volunteered to participate in this study. Participants' age ranged from 20-22 (mean 21) years old. Trained athletes (TA) were regularly trained at least 5 years, three times a week for about 3-5 hours per session while sedentary students (SS) did not have a history of regular exercise or physical activity. Written informed consent was obtained from each participant.

Procedure

All data were collected in Turkey during the year 2014. The participants were fully informed about the study procedures. Age of participants was determined from the date of birth recorded on their national identification cards. This research was performed in accordance with tenets of Helsinki Declaration.

\section{Data Collection}

The peripheral fasting blood samples were collected from both TA and SS. All subjects were given morning appointments and instructed not to eat or drink anything after 22:00 p.m. Their blood samples were taken from the antecubital vein in the at least eight hour period of fasting. $10 \mathrm{ml}$ of blood sample was collected from each participant by using sterile EDTA vacuum tubes. Blood analysis was immediately performed included: RBC,
HGB, HCT, mean cell hemoglobin $(\mathrm{MCH})$ and red blood cell distribution width (RDW), WBC, lymphocyte count, lymphocytes (\%), granulocyte count, granulocyte percentage, monocyte count and monocyte percentage $(\%)$.

\section{Statistical Analysis}

Data analysis was performed through the SPSS (SPSS Inc., Chicago, IL, USA) trial version 17.0 statistical package. Means and SD were computed for all quantitative variables and percentages were computed for categorical variables. The Shapiro-Wilk test was used to inspect for the distributions of the variables. Independent samples t-tests were used to test for group differences. Statistical significance defined at $p<.05$.

\section{Results}

A comparison of the mean $\mathrm{RBC}$ parameters for the TA and SS groups is shown in Table 1. An independentsamples t-test was performed to compare of RBC parameters between the groups. The results of the t-tests revealed that there were significant differences on the HGB $(\mathrm{t}(34)=3.27, p=.002,95 \%$ CI $[0.44,1.87], d=$ $0.10)$, HTC ( $\mathrm{t}(34)=2.56, p=.015,95 \%$ CI [0.61, 5.24], $d=0.16), \mathrm{MCH}(\mathrm{t}(34)=3.50, p=.001,95 \%$ CI $[-0.072$, $2.70], d=0.27)$, and RDW (t (34) $=5.99, p=.00,95 \%$ CI $[1.23,5.50], d=0.51)$. The means of these parameters in the TA group were statistically higher than the SS group. However, the mean of RBC were not significantly different between the two groups $(p>.05)$.

A comparison of the mean WBC parameters for the TA and SS groups is shown in Table 2. An independentsamples t-test was performed to compare of RBC parameters between the groups. The results of the t-tests revealed that there were significant differences on the WBC (t (34) $=-2.77, p=.010,95 \%$ CI $[-1.50,-0.23]$, $d=0.18)$, lymphocyte count ( $\mathrm{t}(34)=-4.55, p=.000$, $95 \%$ CI $[-0.95,0.36], d=0.39)$, lymphocyte percentage $(\mathrm{t}$ (34) $=-5.21, p=.000,95 \%$ CI [-13.66, -5.99], $d=0.44)$, monocyte count $(\mathrm{t}(34)=-4.36, p=.000,95 \%$ CI [-0.28, $0.10], d=0.36)$, and monocyte percentage $(\mathrm{t}(34)=-6.19$, $p=.000,95 \%$ CI $[-2.79,-1.41], d=0.53)$, The means of $\mathrm{WBC}$, lymphocyte count, lymphocyte percentage,

Table 1. Comparison of RBC parameters for TA and SS groups.

\begin{tabular}{|c|c|c|c|c|c|c|}
\hline Variables & $\begin{array}{l}\text { Group } \\
\text { TA } \\
\text { (n=18) } \\
\text { M (SD) }\end{array}$ & $\begin{array}{l}\text { SS } \\
(n=18) \\
M(S D)\end{array}$ & $\begin{array}{l}95 \% \mathrm{Cl} \\
\text { for Mean } \\
\text { Difference }\end{array}$ & $t(34)$ & $p$ & Cohen's d \\
\hline $\mathrm{RBC}\left(10^{\wedge} 6 / \mathrm{uL}\right)$ & $5.41(0.62)$ & $5.10(0.35)$ & {$[-0.03,0.66]$} & 1.87 & .070 & 0.10 \\
\hline HGB (g/dL) & $15.83(1.25)$ & $14.68(0.83)$ & {$[0.44,1.87]$} & 3.27 & $.002 *$ & 0.24 \\
\hline НCT (\%) & $46.04(4.30)$ & $43.13(2.13)$ & {$[0.61,5.24]$} & 2.56 & $.015^{*}$ & 0.16 \\
\hline $\mathrm{MCH}(\mathrm{pg})$ & $29.32(1.16)$ & $27.61(1.72)$ & {$[-0.72,2.70]$} & 3.50 & $.001^{*}$ & 0.27 \\
\hline RDW (\%) & $13.77(0.73)$ & $11.90(1.10)$ & {$[1.23,2.50]$} & 5.99 & $.000^{*}$ & 0.51 \\
\hline
\end{tabular}

Note: $*$; $<.05$ 
Table 2. Comparison of WBC parameters for TA and SS groups.

\begin{tabular}{|c|c|c|c|c|c|c|}
\hline Variables & $\begin{array}{l}\text { Group } \\
\text { TA } \\
(n=18) \\
M(S D)\end{array}$ & $\begin{array}{l}\text { SS } \\
(n=18) \\
M(S D)\end{array}$ & $\begin{array}{l}95 \% \mathrm{Cl} \\
\text { for Mean } \\
\text { Difference }\end{array}$ & $t(34)$ & $p$ & Cohen's d \\
\hline WBC $\left(\times 10^{9} L^{-1}\right)$ & $6.35(0.85)$ & $7.21(1.02)$ & {$[-1.50,-0.23]$} & -2.77 & $.010^{*}$ & 0.18 \\
\hline LC $\left(\times 10^{9} \mathrm{~L}^{-1}\right)$ & $2.11(0.43)$ & $2.77(0.43)$ & {$[-0.95,-0.36]$} & -4.55 & $.000 *$ & 0.39 \\
\hline LP(\%) & $30.11(6.00)$ & $39.94(5.30)$ & {$[-13.66,-5.99]$} & -5.21 & $.000^{*}$ & 0.44 \\
\hline $\mathrm{GC}\left(\mathrm{x} 10^{9} \mathrm{~L}^{-1}\right)$ & $3.71(0.80)$ & $3.39(0.72)$ & {$[-0.21,0.83]$} & 1.22 & .229 & 0.04 \\
\hline GP (\%) & $56.45(7.17)$ & $52.33(5.17)$ & {$[-0.12,8.35]$} & 1.98 & .056 & 0.10 \\
\hline$M C\left(x 10^{9} L^{-1}\right)$ & $0.39(0.15)$ & $0.58(0.10)$ & {$[-0.28,0.10]$} & -4.36 & $.000^{*}$ & 0.36 \\
\hline MP (\%) & 5.68 (1.19) & $7.78(0.81)$ & {$[-2.79,-1.41]$} & -6.19 & $.000 *$ & 0.53 \\
\hline
\end{tabular}

Note: LC; lymphocyte count, LP; lymphocyte percentage, GC; granulocyte count, GP; granulocyte percentage, MC; monocyte count and MP; monocyte percentage and $* ; p<.05$.

monocyte count and monocyte percentage in the SS group were statistically higher than the TA group. However, there was no statistically difference between the two groups in but no statistically significance difference in granulocyte count $(\mathrm{t}(34)=1.22, p=.229,95 \%$ CI $[-0.21,0.83], d=$ $0.04)$ and granulocyte percentage $(\mathrm{t}(34)=1.98, p=.056$, $95 \%$ CI $[-0.12,8.35], d=0.10)$.

\section{Discussion}

The hematological response to acute and chronic exercise has recently been reviewed. Although it is commonly accepted that both acute and chronic exercises induce many hematological changes in humans [13], it is unclear how the long-term effect of regular exercise on hematologic parameters of athletes. To date, however, little attention has been paid to the long-term effect of exercise on hematological parameters in athletes. In this study, we investigated the differences in the hematological parameters between TA group who had a history of basketball, handball and volleyball training for a minimum of 5 years and SS group who did not regular exercise except for daily activity. Our findings partially support our hypothesis and show significant differences between the in HGB, HTC, MCV, RDW, WBC, lymphocyte count, lymphocyte percentage, granulocyte percentage monocyte count, and monocyte percentage between the TA and SS groups. In contrast with what would be expected, there were no significant differences in $\mathrm{RBC}$, granulocyte count, and granulocyte percentage between the groups.

Long-term regular exercise had a significant impact on the physical performance in human [22]. Hematological parameters including RBCs and WBCs are associated with the physical performance of athletes. It is thought that an increase in the concentration of the RBCs indicates an improvement in aerobic performance [23]. The findings from this study demonstrated that RBCs values of both TA and SS groups were within normal range for Turkish people $[24,25]$. The comparison of the mean RBCs values between the TA and SS groups show the means of HGB, $\mathrm{HCT}, \mathrm{MCH}$, and RDW values significantly differed in favor of TA group. However, the mean of RBC values did not differ statistically between the groups. Researches within the past few years have demonstrated that exercise stimulates erythropoiesis and tends to increase the RBCs after competition or training [15,26]. Also, $\mathrm{Hu}$ et al., (2011) also addressed exercise have a positive effect on RBCs indices in human [22]. These statements support our findings of RBCs except for the mean of RBC values. On the other hand, some studies have reported results contrary to the results of this research. In two studies have revealed that athletes have a lower HCT percentage than sedentary subjects. [27,28]. Novosadova indicated that the ratio of hemoglobin to hematocrit remained unchanged during and after moderate $\left(67 \% \mathrm{VO}_{2 \max }\right)$ and low $\left(40 \% \mathrm{VO}_{2 \max }\right)$ intensity aerobic exercise. The results of these studies are inconsistent with our study. In this study, the mean of RBC values did not differ statistically between the groups [29]. The non-significant difference in $\mathrm{RBC}$ counts in between groups may be related to several factors. First, it is possible that exercise programs performed to athletes are not as effective for improving $\mathrm{RBC}$ outcomes as other forms of exercise.

In this study, hematologic variables including $\mathrm{WBC}$, lymphocyte count, lymphocyte percentage, monocyte count, and monocyte percentage were significantly lower in TA group. Although the granulocyte count and percentage were higher in SS group, these parameters did not differ significantly between the groups. Scientific evidence exists that WBCs play a crucial role in the immune system [7,11]. The high circulating levels of WBCs and their subtypes is closely associated with increased infection or inflammation as well as coronary heart disease and type 2 diabetes [30,31]. All mean values in both groups were within normal range for Turkish people despite the statistically significant differences between the 
groups [24,25]. In literature, previous research has shown that there are the inter-relationships between exercise and immune function [32]. Some researcher indicated that the lymphocyte concentration increases during exercise bouts but it may fall baseline values found before exercise after exercise [11]. In addition, other researchers addressed decreased or no changed in WBCs values of athletes both during exercise and after $[14,33]$. Taken together, these reports and our results revealed that regular exercise has no adverse effect on the immune system in the long term.

\section{Conclusion}

In summary, our findings show that athletes participating in the long-term regular exercise may have the high level of RBC subtypes concentration and the low level of WBC subtypes concentration when compared to their sedentary peers. Because their hematologic values remain within the reference range for healthy people, these differences do not pose any serious clinical problems for athletes. The high RBC and low WBC subtypes values of athletes may be explained by chronic adaptation to long-term exercise. As a result, to participate in long- term regular exercise training affects positively the hematological parameters. Future large scale research is needed to further confirm these results in both athletes and other populations.

\section{Highlights}

- Regular exercise has no adverse effect on the immune system in the long term.

- $\quad$ Long-term training can effects on concentration of hemoglobin, percentage of hematocrit, mean cell hemoglobin, and red blood cell distribution width.

- White blood cells count, lymphocyte count, lymphocyte percentage, monocyte count and monocyte percentage in sedentary men are higher than well-trained men athletes.

\section{Acknowledgment}

We gratefully acknowledge the help of all the participant who took part in the study.

\section{Conflict of interests}

The authors declare that they have no conflict of interest.

and cytokines. Exp. Hematol. 2008;36(2):216-23.

14.Carlson LA, Lawrence MA, LeCavalier K, Koch AJ. Salivary lymphocyte responses following acute anaerobic exercise in a cool Environment. J Strength Cond Res, 2017;31(5):123640.

15.Mairbäurl H. Red blood cells in sports: effects of exercise and training on oxygen supply by red blood cells. Front Physiol, 2013;4:1-13.

16.Galun E, Burstein R, Assia E, Tur-Kaspa I, Rosenblum J, Epstein Y. Changes of white blood cell count during prolonged exercise. Int J Sports Med, 1987;8(04): 253-55.

17.Ohno H, Sato Y, Yamashita K, Doi R, Arai K, Kondo T, Taniguchi N. The effect of brief physical exercise on free radical scavenging enzyme systems in human red blood cells. Can J Physiol Pharmacol, 1986;64(9):1263-65.

18.Ahmadizad S, El-Sayed MS. The acute effects of resistance exercise on the main determinants of blood rheology. J Sports Sci, 2005;23(3): 243-49.

19. Shapoorabadi YJ, Vahdatpour B, Salesi M, Ramezanian H. Effects of aerobic exercise on hematologic indices of women with rheumatoid arthritis: A randomized clinical trial. $J$ Res Med Sci, 2016;21:9-15.

20.Bodary PF, Pate RR, Wu QF, McMillan GS. Effects of acute exercise on plasma erythropoietin levels in trained runners. Med Sci Sports Exerc, 1999;31(4):543-46.

21.Müller UM, Walther C, Adams V, Mende M, Adam J, Fikenzer K, et al. Long term impact of one daily unit of physical exercise at school on cardiovascular risk factors in school children. Eur J Prev Cardiol, 2016;23(13):1444-52.

22.Hu M, Finni T, Xu L, Zou L, Cheng S. Effects of resistance training on biomarkers of bone formation and association with red blood cell variables. $J$ Physiol Biochem, 2011;67:351358.

23.Schumacher YO, Schmid A, Grathwohl D, Bültermann D, Berg A. Hematological indices and iron status in athletes of various sports and performances. Med Sci Sports Exerc. 2002;34(5):869-75.

24.Tekkeşin N, Bekoz H, Tukenmez F. The largest reference 
range study for hematological parameters from Turkey: A case control study. Journal of Clinical and Experimental Investigations, 2014;5(4):548-52.

25.Kilınc M, Celik A, Sahin E, Tolun FI. Haematological reference values according to age groups and sex for Kahramanmaras province population. KSU Tip Fak.Der, 2014;9(1):39-44.

26.Ozal M. Effects of a yearlong wrestling training season on biochemical blood parameters of elite wrestlers. Anthropologist, 2014;18(3):691-96.

27. Weight LM, Alexander D, Elliot T, Jacobs P. Erythropoietic adaptations to endurance training. Eur J Appl Physiol Occup. Physiol, 1992;64(5):444-48.

28.Sawka MN, Convertino VA, Eichner ER, Schnieder SM, Young AJ. Blood volume:importance and adaptations to exercise training, environmental stresses, and trauma/ sickness. Med Sci Sports Exerc, 2000;32(2):332-48.

29. Novosadova J. The changes in hematocrit, hemoglobin, plasma volume and proteins during and after different types of exercise. Eur J Appl Physiol Occup.Physiol, 1977;36(3):22330

30.Madjid M, Fatemi O. Components of the complete blood count as risk predictors for coronary heart disease: in-depth review and update. Tex Heart Inst J 2013:40(1):17-29.

31. Vozarova B, Weyer C, Lindsay RS, Pratley RE, Bogardus C, Tataranni PA. High white blood cell count is associated with a worsening of insulin sensitivity and predicts the development of type 2 diabetes. Diabetes, 2002;51(2):455-61.

32.Natale VM, Brenner IK, Moldoveanu AI, Vasiliou P, Shek P, Shephard RJ. Effects of three different types of exercise on blood leukocyte count during and following exercise. Sao Paulo Medical Journal, 2003;121(1):9-14.

33.Fry RW, Morton AR, Crawford GPM, Keast D. Cell numbers and in vitro responses of leucocytes and lymphocyte subpopulations following maximal exercise and interval training sessions of different intensities. Eur J Appl Physiol Occup.Physiol, 1992;64(3):218-27.

\section{Information about the authors:}

Koç H.; Prof.; http://orcid.org/0000-0003-2867-9775; hkoc@gmail.com; Department of Coaching Education, Faculty of Sport Sciences, Çanakkale Onsekiz Mart University; Canakkale, 17020, Turkey.

Özen G. (Corresponding author); PhD.; http://orcid.org/0000-0001-5756-653X; gokmenozen44@gmail.com; Department of Physical Education and Sports Teaching, Faculty of Sport Sciences, Çanakkale Onsekiz Mart University; Canakkale, 17020, Turkey.

Abanoz H.; MD.; http://orcid.org/0000-0002-4415-6723; hsn.abanoz@gmail.com; Department of Coaching Education, Faculty of Sport Sciences, Çanakkale Onsekiz Mart University; Canakkale, 17020, Turkey.

Pulur A.; Assoc. Prof.; http://orcid.org/0000-0003-2022-3300; a.pulur@gazi.edu.tr; Department of Physical Education and Sports Teaching, Faculty of Sport Sciences, Gazi University; Ankara, 06560, Turkey.

Cite this article as: Koç H, Özen G, Abanoz H, Pulur A. Comparative analysis of hematological parameters in well-trained athletes and untrained men. Pedagogics, psychology, medical-biological problems of physical training and sports, 2018;22(5):260-264. doi:10.15561/18189172.2018.0506

The electronic version of this article is the complete one and can be found online at: http://www.sportpedagogy.org.ua/index.php/PPS/issue/archive

This is an Open Access article distributed under the terms of the Creative Commons Attribution License, which permits unrestricted use, distribution, and reproduction in any medium, provided the original work is properly cited (http://creativecommons.org/licenses/by/4.0/deed.en).

Received: 01.08 .2018

Accepted: 28.08.2018; Published: 30.09.2018 